\title{
AFOXÉS: MANIFESTAÇÃO CULTURAL BAIANA OU PERNAMBUCANA? NARRATIVAS PARA UMA HISTÓRIA SOCIAL DOS AFOXÉS.
}

\author{
Ms. Ivaldo Marciano de França Lima'
}

\begin{abstract}
Resumo: Inexistentes nas ruas recifenses e olindenses nos anos 1970, os afoxés constituem nos dias atuais presença efetiva nos eventos do movimento negro e carnaval pernambucano. Paulatinamente ocuparam espaços na sociedade e constituem mais de sessenta grupos que realizam atividades anualmente. Ainda hoje, porém, são questionados por setores da intelectualidade por sua "origem” baiana. Tal argumento procura deslegitimar o afoxé enquanto manifestação cultural merecedora de atenções e recursos do poder público. Mas de onde vieram os afoxés? Quem são as pessoas que os fazem e onde atuam? Este trabalho objetiva discutir a história dos afoxés em Pernambuco entre os anos de 1980 a 2000, discutindo a historiografia e as interpretações que os movimentos negros construíram.
\end{abstract}

Palavras-chave: Afoxés; Cultura afro-brasileira; Carnaval; Pernambuco

\begin{abstract}
Non-existent in the streets of Olinda or Recife in the 1970's, the "afoxés" are today an important presence in the events promoted by the Black Movement and in Pernambuco's "Carnaval”. Gradually they have occupied a clear space in the society and they constitute more than sixty groups that carry out activities annually. Still today, however, they are questioned by sectors of the intellectuality for its "bahian origin". Such argument looks for to take the legitimacy from "afoxé" as a cultural manifestation allowed to attention and resources from the public power. But where do the "afoxés" really come from? Who are the people who make them and where do they act? This work will discuss the history of afoxés in Pernambuco between the 1980's and 2000. It will also discuss the historiography and the interpretations that the black movements had build about it.
\end{abstract}

Key-words: Afoxés; Afro-Brazilian culture; Carnaval; Pernambuco

O carnaval do Recife possui diversas manifestações culturais que se apresentam nas ruas, palcos e passarelas durante os três dias do reinado de momo. Dentre estas manifestações, os afoxés são as que podem ser consideradas mais

Doutorando em História pela Universidade Federal Fluminense. E-mail para contato: ivaldomarciano@yahoo.com.br 
recentes, pois começaram a aparecer no Recife no início dos anos 1980. Mas o que são os afoxés? Existem diferentes sentidos para esta palavra, podendo designar a manifestação (um "bloco" carnavalesco), o ritmo e um instrumento musical. A discussão sobre os afoxés em Pernambuco circula, grosso modo, em torno da origem dos grupos, e da sua relação íntima com a religião dos orixás (xangô ou candomblé). A existência dos afoxés em Pernambuco suscitou muitos debates e polêmicas em torno da legitimidade destes grupos, e se os mesmos deveriam ou não ser bem recebidos na "capital do frevo", uma vez que estamos falando de uma manifestação cultural que não é "originária” destas terras. A origem dos afoxés é tomada como um dos principais argumentos para se conferir ou não legitimidade e reconhecimento dos novos grupos que surgem em um ambiente fortemente marcado pela discussão de autenticidade, legitimidade e pureza. Diriam alguns dos mais exaltados intelectuais pernambucanos, guardiões da tradição, que não se deveria dar espaço a uma manifestação cultural oriunda de outras paragens. Em contrapartida, muitos militantes do movimento negro pernambucano tomaram outros caminhos, e criaram argumentos para bater de frente com esses intelectuais justificando a existência dos grupos de afoxé, seja pela idéia de que se trata de uma manifestação essencialmente negra, seja argumentando que maracatus e afoxés tiveram uma origem comum. Como se pode observar, a origem dos afoxés está no centro dos debates em questão.

\section{VAMOS ÀS ORIGENS!}

A busca pela origem foi a maneira pelo qual diferentes estudiosos analisaram práticas e costumes culturais afro-descendentes na perspectiva de poder explicá-las em sua complexidade. O início representaria uma suposta pureza ainda não corrompida, onde estaria resguardada sua essência, maneira pela qual se poderia entender tal prática ou costume. Assim, para compreender as manifestações bastaria saber de sua origem, e este foi o caminho escolhido por vários folcloristas para explicar os maracatus, a capoeira, e os afoxés, por exemplo. Essa compreensão, no entanto, percebe as práticas culturais em sua perspectiva estática e imobilizadora. Ora, se a origem "explica” o presente, não há por que aceitar as mudanças que ocorrem. A alteração ou modificação em uma prática e costume, por mais que represente para os "detentores do saber fazer” uma adaptação a uma dada realidade ou contexto, será sempre tida como "descaracterização” ou deturpação para aqueles que estão presos à perspectiva da busca da origem e da pureza. A mudança ou a adaptação ao presente, produzida pelos que fazem as manifestações, é vista como fruto de forças externas, alheias à vontade dos praticantes, e deve ser combatida pelos "guardiões" da cultura popular e do folclore, sempre tomados como em perpétuo risco de desaparecimento. 
Há uma quantidade considerável de estudiosos que trilharam esse caminho: explicar as práticas e costumes a partir da origem. No tocante aos maracatus-nação poderia citar diversos autores, o que já discuti de modo exaustivo em outros trabalhos. ${ }^{2}$ Não seria diferente no caso da capoeira, uma vez que seu "surgimento" foi objeto de intensas polêmicas. Há os que afirmam ter sido esta de origem africana (e nesse caminho aparecem os "refinamentos da pesquisa" que vão apontar uma origem banto ou uma invenção "africana” indistinta). E também os que apontam para uma origem essencialmente brasileira da capoeira, e nesse caso as contendas pelo "berço primordial" e primazia são disputados por intelectuais e praticantes baianos, cariocas e pernambucanos. ${ }^{3}$

No tocante aos afoxés, há um quase consenso tácito de que são originários da Bahia, heranças dos diferentes povos africanos que a essa terra vieram sob a condição de escravos. Os escritos de Edison Carneiro, no entanto, apontam para uma origem desconhecida, mesmo ressaltando serem baianos os grupos que existiam no país. Nesse sentido, mesmo considerando as observações de Edison Carneiro, o afoxé seria uma manifestação cultural baiana, e como tal, sua adoção em outros estados brasileiros constituiria uma “mudança de planos” daqueles que originariamente criaram essa prática.

Raphael Filho afirma que os folguedos negros existentes nos últimos dez anos do século XIX foram tratados genericamente como afoxés. Esta afirmação nos traz um dado complicador, qual seja, o de que sequer sabemos como seriam, de fato, os grupos de afoxés do período, posto que o termo servia para designar várias manifestações culturais carnavalescas diferentes. ${ }^{4} \mathrm{~A}$ esta afirmação somese também uma outra deste mesmo autor, sobre os afoxés, de que os “jornalistas não tinham nenhuma preocupação em descrever as suas passeatas, principalmente por recair sobre esse tipo de manifestação as maiores críticas das elites da época”. ${ }^{5}$

Além de não haver descrições sobre os grupos, o termo "afoxé" constituiria, no final do século XIX, palavra polissêmica, a exemplo de outras tantas usadas nesse período, como batuques, sambas e maracatus. Ainda sobre os afoxés, Raphael Filho destaca que pouco se sabe sobre os grupos no período que vai desde o final do século XIX até os anos $1930 .{ }^{6}$ Isto, porém, não impediu os intelectuais de escreveram sobre os afoxés, sobretudo no que diz respeito aos usos e sentidos dos afoxezeiros que integravam os grupos. Um consenso que se estabeleceu entre estes estudiosos que escreveram sobre esta manifestação cultural diz respeito ao seu estreito vínculo com o sagrado. Os afoxés já vieram ao mudo atados aos terreiros de candomblé, aspecto que servirá de justificativa para discursos em busca da legitimidade da prática tanto em Pernambuco como na Bahia. 


\section{AFOXÉS: SAGRADOS DESDE A “ORIGEM”?}

Carneiro e Maynard, ao descreverem os afoxés, sinalizaram a presença de fortes características religiosas nos grupos. Os afoxés, para ambos, constituem uma espécie de cortejo que canta em língua litúrgica "africana”, sempre pedindo permissão aos orixás antes de desfilar pelas ruas durante o carnaval. Raul Lody também sugere uma relação naturalizada entre os afoxés e os terreiros de candomblés afirmando que a própria origem da manifestação estaria nas festas de Oxum, realizadas no continente africano. ${ }^{7}$ Guerreiro e Risério também indicam este caminho, e abrem o precedente para pensarmos que os grupos da atualidade existentes na Bahia não correspondem mais ao que eram no passado.

Raphael Filho, no entanto, indica que os afoxés resultaram de um dos muitos tipos de grupos carnavalescos baianos denominados por candomblés: "No nosso entendimento, esses grupos se transformariam nos afoxés". ${ }^{8}$ As origens dos afoxés, portanto, residiriam nas mudanças que ocorreram em grupos diversos que existiram na Bahia. Ressalte-se que, mesmo fruto das mudanças, o afoxé é posto de modo implícito como "criação baiana".

As palavras de Maynard são bastante esclarecedoras e nos permitem concluir que seriam os afoxés uma espécie de procissão religiosa em pleno carnaval, ou “candomblés de rua”. Suas representações sobre esta questão possuem força suficiente para pensarmos nas imagens de negros e negras dançando sempre sob a permissão dos orixás:

O afuxé ao sair no carnaval baiano não se mistura com a rodade-samba, com as embaixadas, a capueira, o bumba-meu-boi, com as batucadas alucinantes, porque ele tem características inconfundíveis e dentre elas se destaca a preparação, sem dúvida um ritual religioso (...) o afuxé tem muito de africano: canta em língua nagô, música de ritmo contagiante que enreda o simples espectador de rua a acompanhar com o corpo, quando desfilam pelas vielas, ruas e avenidas da capital baiana (...) Antes de "entrar na dança” há uma preparação ritualística que os afuxés realizam, mostrando-nos o caráter religioso desta dança que torna profana ao partilhar do carnaval. Pode-se mesmo perceber uma mudança sensível nas músicas: quando ainda no terreiro para o "padé de Exu”, elas são tristes, logo que passam a desfilar pelas ruas, são alegres, vivas e contagiantes. O afuxé em conclusão é um candomblé adequado ao carnaval, iniciando com um sacrifício, um despacho para que Exu não interrompa as festividades carnavalescas, é o que pedem nesse "padé de Exu", quando, no centro do terreiro está o que ele mais aprecia: farofa com azeite de dendê. ${ }^{9}$ 
A força das palavras deste folclorista marca de modo ímpar a leitura dos que nunca viram um afoxé em suas vidas, pois muitos ao se depararem com um destes grupos, buscam a presença do candomblé. O elemento religioso é aspecto fundamental, nas palavras de Edison Carneiro:

Todos eles fazem obrigações religiosas (de propiciação) antes de sair à rua e, em desfile, cantam hinos (cantigas) de exaltação às divindades do candomblé - um repertório cuidadosamente escolhido, composto apenas de hinos fracos, ou seja, que apenas homenageiam os orixás, sem os induzir a descer na cabeça de alguém. ${ }^{10}$

Mas o que é um afoxé? Como são organizados os personagens em um desfile? Temos realmente a impressão de estarmos diante de um candomblé de rua ao nos deparamos com um destes grupos? Mais uma vez recorro a Edison Carneiro, para indicar como foi descrito o afoxé, segundo suas próprias palavras:

A formação ideal do afoxé seria a seguinte: - arautos, guarda branca, rei e rainha, babá l'ótin, papai cachaça em nagô (agora se diz Babalôtim ou Babalotinho), um boneco levado por um adolescente que dança com grande independência de movimentos - o equivalente masculino da boneca do maracatu. Estandarte, guarda de honra, charanga de ilus (atabaques), agogôs e cabaças. Aos lados do cortejo desfilavam as mulheres, em coluna por dois. ${ }^{11}$

Em outra rápida descrição este mesmo autor nos mostra que mesmo nos afoxés existem adaptações, alterações de personagens e criações:

A frente do desfile vem um grupo de caçadores, seguido pelo Babalôtim ou Babalôtinho, um jovem que carrega um boneco e dança independentemente dos demais - versão masculina da Dama do Paço do maracatu. Segue-se a porta-bandeira, com a sua guarda de honra, e atrás vem a charanga. Fecham a marcha vassalos e crioulas, em trajes típicos. Aqui, porém, nem sempre há rei e rainha. O desfile perdeu o seu objetivo - não é mais o cortejo real, embora o sugira o seu esplendor (...). ${ }^{12}$

Agora não mais temos “a formação ideal”, mas a "perda dos objetivos”, o que para um bom folclorista é percebido nas mudanças, operadas pelos próprios afoxezeiros. O que diria Edison Carneiro dos grupos de afoxés pernambucanos? Para essa interrogação não teremos respostas, posto que os afoxés surgem em Pernambuco no início dos anos 1980 (ou ressurgem, como insistem em dizer alguns afoxezeiros que entrevistei). 
No tocante às mudanças, Raul Lody aponta para a perspectiva de que elas ocorrem devido ao fato de serem os afoxés uma tradição sustentada pela repetição acrítica, tomando de empréstimo o conceito formulado por Câmara Cascudo em Vaqueiros e cantadores. ${ }^{13}$ Pode-se atestar esta concepção de cultura não apenas nos variados termos que denunciam a influência teórica dos antropólogos evolucionistas, a exemplo de sobrevivência totêmica, totem, totemismo e reminiscência, mas também em um trecho de sua obra sobre os afoxés:

As letras das melodias dos afoxés têm no yorubá a língua principal. Outros dialetos menores são observados, incluindo também a presença de alguns termos em português. Grandes variações são encontradas nas letras, que variam de acordo com a interpretação do diretor de canto ou devido ao adiantado estado de corrutela, afetando os termos originais. A maioria das letras desses orôs nada significam para as pessoas que cantam. O desconhecimento dos significados das palavras abrange quase que a totalidade das pessoas ligadas a essa prática (...). ${ }^{14}$

Não creio que nos dias atuais algum estudioso afirme ser uma prática ou costume mantido apenas à custa de simples repetição mecânica, e que não tenha significados para aquele que o faz. Stuart Hall, ao discutir sobre as interpretações presentes na codificação e decodificação das idéias, códigos e discursos, afirma que não há uma forma única de recepção destas entre os indivíduos. Para ele "os códigos de codificação e decodificação podem não ser perfeitamente simétricos”, ${ }^{15}$ principalmente quando os indivíduos se encontram em níveis distintos no que tange à identidade e ao compartilhamento de códigos culturais. Assim sendo, por mais que as letras dos afoxés sejam cantados em uma língua desconhecida para o afoxezeiro, este atribuirá sentidos para a música, dando para a mesma uma feição e um significado que tornam o ato de cantar uma ação consciente e não um ato impensado ou reminiscência de tempos imemoriais.

As influências dos antropólogos evolucionistas nos textos de Raul Lody são visíveis e dignas de nota, sobretudo quando este estudioso afirma existirem, mesmo que "rareando ano a ano" sobrevivências totêmicas nos afoxés. O camelo, símbolo dos dois afoxés denominados Filhos de Gandhy (há o grupo baiano, bastante afamado, e o carioca, sediado na Saúde, próximo à Estação Central do Brasil), é a representação, para ele, do totem, palavra bastante repetida ao longo de seu trabalho. ${ }^{16} \mathrm{O}$ totem, segundo Arthur Ramos, é a personificação do ancestral primeiro de um determinado grupo humano primitivo: “(...) no primitivo aspecto religioso do totemismo, o selvagem julga que descende diretamente do seu totem e até, em alguns casos, se identifica com o mesmo. Dai uma série de restrições em relação ao totem (...).” ${ }^{17}$ 
Antônio Risério, intelectual baiano e compositor dos bons, ao discorrer sobre os afoxés também indicou a religião como marca presente nos grupos que observou. Sua conclusão, contudo, decorre não somente do que viu, mas do que leu e escutou, segundo suas próprias palavras:

Olhando mais de perto a transação mística dos afoxés é bom notar que eles já nasceram ligados a terreiros de candomblé e dirigidos por babalorixás ou outras personalidades do culto. Edison Carneiro cita alguns exemplos, como o do Lordes Ideais, fundado pelo doqueiro José do Gude, ogã do candomblé do Bate-Folha (...) Antes de iniciar o desfile, realiza-se, nos afoxés, uma cerimônia religiosa: o padê, despacho de Exu, entidade mágica que, intermediando entre nós humanos e os orixás, pode fazer com que toda e qualquer festa transcorra em paz e em alegria (....). ${ }^{18}$

Um dos mais significativos depoimentos sobre a relação íntima dos afoxés com o candomblé e os terreiros foi dado, para Antônio Risério, por um popular baiano. Batata, mestre sambista soteropolitano, ao ser indagado sobre sua opinião a respeito de todas as transformações que ocorriam no cenário musical baiano, afirmou no início que aprovava o que vinha acontecendo, em relação aos novos blocos afros que estavam sendo criados. Porém, quando questionado a respeito dos afoxés, expressou ser contrário às inovações e à perda de uma tradição:

(...) Ok, mas logo Batata mudaria de opinião, descontente com o rumo tomado pelos afoxés, no rastro do Badauê. Sua crítica, no fundo, é semelhante à de Eduardo de Ijexá, ambas representativas do que os mais velhos pensam sobre o assunto. Eles se rebelam contra as inovações encontráveis nos novos afoxés. Batata reclama que, no tempo dele, o afoxé era uma coisa fechada, com origem numa casa de candomblé, formado por pessoas ligadas a determinado terreiro ou pai de santo, etc. Centrando sua crítica no Badauê, Batatinha também recorda como era um antigo afoxé criado também no Engenho Velho: "o afoxé lá do Engenho Velho, por exemplo, saía da casa de um pai santo, seguia uma linha dentro da seita". E para ele é inadmissível que o Badauê, também nascido no Engenho Velho, não mantenha a tradição. ${ }^{19}$

As mudanças são constantes nas práticas humanas, mesmo na Bahia, o lugar apontado por alguns estudiosos como "berço dos afoxés”. Mas essa idéia de mudança não é encontrada de modo fácil nos textos daqueles que escrevem sobre manifestações culturais. Para Raphael Filho, conforme já observei, os afoxés são fruto de mudanças. Isto, no entanto, não impediu que este autor ficasse 
imune às representações em torno da idéia de serem estes grupos uma manifestação cultural fortemente baseada (e apoiada) na religião. Para ele, os afoxés constituem espécie de prática sagrada em meio à folia do carnaval, assim como quase não sofreram mudanças em seus traços:

Até 1930 a forma de sair às ruas dos afoxés, as únicas manifestações negras remanescentes do século passado, não sofreram grandes modificações. Os afoxés têm como principal característica uma certa profanação dos cultos do candomblé, visto que levam a público nos dias de carnaval uma ritualização dessa religião afro-brasileira. ${ }^{20}$

Mesmo nas representações dos intelectuais e estudiosos contemporâneos, como é o caso de Goli Guerreiro, a relação dos afoxés com o sagrado permanece forte e praticamente inalterada, por mais que as práticas dos afoxezeiros indiquem outros rumos. Para Goli Guerreiro os afoxés:

(...) Podem ser descritos como "candomblés de rua”. Quase todos os membros dos afoxés se vinculam ao culto. Seus músicos são alabês, suas danças reproduzem as dos orixás, seus dirigentes são babalorixás (chefes de terreiro que dominam a língua ioruba) e o ritual do cortejo obedece à disciplina da tradição religiosa. No entanto, a preservação dos fundamentos secretos da religião é observada. A orquestra chamada "charanga”, que executa o ritmo ijexá, é composta de agogôs, xequerês e três tipos de atabaques (rum, rumpi e lê), tal como nas cerimônias religiosas (...) Os afoxés trouxeram para o espaço do carnaval o repertório musical e a estética dos candomblés. ${ }^{21}$

Diante do que muda, daquilo que "deixa de ser o que era no passado", a interpretação mais recorrente que encontro é de incompreensão para com aqueles e aquelas que operaram as práticas. Os afoxezeiros baianos adaptaram-se aos novos tempos, pondo seus costumes em sintonia com o quotidiano em que vivem e sofrendo outras influências da sociedade na qual estão imersos. Goli Guerreiro escolhe outro caminho, no entanto. Mostra os novos grupos de afoxés recém-surgidos como "diferentes” do que se observava no passado, e aponta sua preferência para o Filhos de Gandhy, indicando-o como o último sobrevivente dos verdadeiros afoxés do passado. As palavras da autora são bastante significativas para ilustrar esta conclusão:

(...) Outros afoxés, formados entre os anos 70 e 80, como o Oju Oba, Olori, e o mais famoso deles, o Badauê, já não obedeciam à tradição religiosa e a participação das pessoas ligadas aos terreiros não era rigorosamente observada (...). ${ }^{22}$ De todos os 
antigos afoxés que a Bahia conheceu ao longo do século, somente o Gandhy se mantém vivo e fiel a todos os elementos rituais, reafirmando continuamente a relação visceral entre o carnaval negro de Salvador e o candomblé, além de servir de inspiração para novos afoxés (...). ${ }^{23}$

A “tradição" da intimidade dos afoxés com o candomblé continua sendo mantida pelo Filhos de Gandhy. Os demais grupos perderam os vínculos que possuíam, tornando-se afoxés sem tradição religiosa. Mais à frente discutirei como esta afirmação, presente também em outros autores, será utilizada pelos afoxezeiros pernambucanos para indicar a seriedade de seus grupos, e, por conseguinte, a diferença fundamental que lhes permitirá constituir-se em "legítimos e autênticos”, mesmo estando em Pernambuco. Mas de onde surgiram os afoxés? Como este debate sobre as origens foi feito pelos estudiosos? Afinal de contas os afoxés são mesmo baianos por natureza?

\section{AFOXÉS: A “ORIGEM BAIANA”, REMINISCÊNCIA DAS COROA- ÇÕES DOS REIS E RAINHAS DE CONGO.}

Entre os estudiosos que escreveram sobre os afoxés, indicando suas origens destaca-se Alceu Maynard devido, sobretudo, à relevância de suas obras entre os folcloristas brasileiros. Para este, os afoxés surgiram de modo semelhante aos maracatus-nação, e intimamente ligados aos candomblés:

O afuxé (sic) baiano tem origem semelhante a do maracatu pernambucano. Ambos vem da arqueocivilização negra. No presente encontra-se maior número de traços sagrados no afuxé do que no maracatu cuja secularização dia a dia se torna maior. Seria o sagrado participando do profano no carnaval, porque o afuxé é uma obrigação religiosa que os membros dos candomblés, principalmente os de origem jeje-nagôs, terão que cumprir, cuja saída no período momístico será feita “nem que seja por perto do terreiro”. ${ }^{24}$

Nessa perspectiva, os afoxés constituem uma criação baiana regida por vínculos estreitos com os candomblés, considerados uma prática religiosa em meio ao carnaval, diferente dos maracatus pernambucanos, irmão de uma origem comum (as coroações dos reis e rainhas do congo), mas que vem em processo de "secularização", ou seja, perdendo os vínculos com o sagrado. O texto de Alceu Maynard revela sua concordância com a idéia de origem, tão comum entre diversos folcloristas. Edison Carneiro, diferente de Alceu Maynard, não afirma de forma explícita a origem baiana. Em um de seus muitos trabalhos sobre o assunto mostra a existência de dúvidas quanto à origem dos afoxés: 
O afoxé da Bahia tem desorientado os pesquisadores, quer quanto às suas origens, quer quanto ao seu significado. Donde teriam surgido esse estranho cortejo de negros que tocam atabaques e entoam canções, em nagô, em louvor às divindades do candomblé? ${ }^{25}$

Em outro trabalho, porém, Edison Carneiro não enfatiza a existência de tais dúvidas em torno da origem dos afoxés, preferindo discorrer sobre sua origem nas festas dos reis e rainhas do congo, ao afirmar que “... Menos conhecido do que o maracatu do Recife, também constitui uma reminiscência do cortejo dos reis do congo o afoxé da Bahia”. ${ }^{26}$ Edison Carneiro também indicou que os afoxés possuem origem semelhante aos maracatus. Comentando sobre a suntuosidade dos grupos baianos nos fins do século XIX, este autor, no que diz respeito às semelhanças entre afoxés e maracatus, afirmou:

(...) Então foi possível relaciona-los aos maracatus de Pernambuco, de que são a contraparte baiana, e identificá-los, a uns e a outros, como rebentos longínquos dos antigos cortejos dos reis do congo, tão em voga durante a escravidão. ${ }^{27}$

A relação com os maracatus recifenses para explicar os significados do afoxé não é exclusiva de Edison Carneiro. Raphael Filho também indicou que estas manifestações possuem as mesmas origens.

(...) Os autores consultados concordam com o fato dos afoxés terem suas origens comuns aos maracatus de Recife, isto é, os cucumbis e os desfiles dos Reis Congos. Esses fazem parte de uma multiplicidade de manifestações conhecidas como Ciclo dos Reisados, tendo sua ocorrência entre o Natal e o Carnaval. (...) Notamos isso com maior clareza observando os diversos maracatus de Recife, também conhecidos como Maracatus de Nação, e seus diferentes totens representativos dos grupos. ${ }^{28}$

Além de apontar uma mesma origem para afoxés e maracatus, Raphael Filho revela suas influências teóricas da antropologia evolucionista ao utilizar-se do conceito de totem, deixando implícita a idéia de que os maracatus constituem uma sobrevivência totêmica. Raul Lody também assinalou existir laços entre os maracatus e os afoxés, chegando mesmo a discorrer sobre uma situação, a meu ver bastante inusitada para um antropólogo, que é a de estabelecer uma conclusão a partir de um único depoimento, mesmo que este não tenha fornecido subsídios suficientes para tal questão:

(...) Outros subsídios sobre o afoxé ocorreram em Recife, quando em pesquisa efetuada no terreiro do Pai Adão (...). As infor- 
mações sobre o afoxé chegaram através dos elos que unem esse terreiro ao grupo de maracatu Leão Coroado (...). Essa agremiação encontra no terreiro de Pai Adão importante base para as sobrevivências religiosas do grupo (...). Observando os muitos instrumentos no interior do peji, constatei o típico ilu do Gexá, o mesmo encontrado nos conjuntos dos afoxés baianos. A meu pedido o instrumento foi executado, as mesmas características na maneira de percutir o ilu, bem como a batida peculiar do Gexá foram constatadas. Indagado sobre o uso do ilu dentro do maracatu o informante disse o seguinte: “esse instrumento pertence a um outro tipo de brincadeira de rua. Os orixás Exu, Xangô e Iansã são os patronos dessas festas. Especialmente Yansã, divindade irrequieta, temperamental e que gosta muito de animação toma sempre a frente dessas brincadeiras, incluindo também o maracatu”. A brincadeira de rua indicada pelo informante é naturalmente o afoxé, que talvez tenha sido assimilado pelos maracatus.. ${ }^{29}$

Diante do depoimento dado pelo informante de Raul Lody, não teríamos nenhuma condição de afirmar ou concluir sobre a existência dos afoxés em Pernambuco, a não ser que se pense que "os mantenedores das tradições” não possuem idéias ou conhecimentos sobre o seu passado. Conforme observamos, Raul Lody foi quem concluiu ter existido o afoxé em Pernambuco e não o informante. A isto devo acrescentar uma discussão feita por Fredrik Barth ao indicar que “(...) devemos tentar olhar para nosso objeto de estudo sem que nossa visão seja excessivamente determinada pelas convenções antropológicas herdadas”, ${ }^{30}$ ou seja, faz-se necessário estabelecer uma distância entre o que se quer com a pesquisa de campo e o que se ouve de fato dos informantes. Sei que é humanamente impossível ir ao campo sem nossos conhecimentos sobre o objeto em questão, mas não se pode dialogar com os informantes na perspectiva de forçar situações ou querer ouvir destes as respostas para os problemas que são colocados pelo pesquisador. Saber ouvir e analisar o que se ouve deve ser sempre um exercício e uma prática constante para o antropólogo e o historiador em busca de informações. ${ }^{31}$

Guerra Peixe também discutiu sobre a questão em torno da relação entre maracatus e afoxés, mesmo que de modo circunstancial, indicando que ambas as manifestações seriam próximas por terem origem na coroação dos reis e rainhas do congo. Em célebre estudo sobre os maracatus, Guerra Peixe apontou que entre os participantes desta prática a utilização da palavra "afoxé” era restrita aos "mais entendidos", o que lhe permitia concluir que, no passado, esse era o termo utilizado para nomear os grupos pernambucanos. Tal questão, a da estreita vinculação entre maracatus e afoxés, permitiu que vários militantes do movimen- 
to negro pernambucano se apropriassem dessa versão, reinterpretando-a para legitimarem a existência do afoxé na "terra do frevo":

(...) No momento, porém, é oportuno revelar que em nossas indagações num maracatu, assinalamos a palavra "afoxé" ou melhor, "afoxé de África”, como remoto designativo do folguedo - expressão hoje apenas lembrada por alguns participantes dos mais entendidos. Sabemos que o vocábulo "afoxé" - do sudanês àfohsheh - indica, na Bahia, a espécie de maracatu salvadorense (sic) e nomeava, como explica Arthur Ramos, as festas profanas dos terreiros baianos. A palavra apareceu no Recife, certamente, em virtude da influência religiosa que os sudaneses exerceram sobre os bantos. "Nação" seria, então, o designativo do grupo administrado por governador negro; "afoxé”, ou "afoxé de África”, a festa profano-religiosa efetuada pela nação no momento oportuno. Os autores que se ocuparam do maracatu recifense não registram "afoxé" nos seus apontamentos, fazendo-nos supor que a expressão se tenha restringido ao âmbito dos seus participantes (...) (os negritos e as aspas são do autor). ${ }^{32}$

Este trecho da obra célebre e já citada de Guerra Peixe deve ser analisado sob diversos aspectos, principalmente no que diz respeito ao fato de se tratar de um autor que foi transformado em "autoridade” para dizer o que é e o que não é maracatu. Ao longo de suas pesquisas entre os anos de 1949 a 1952, época em que residiu no Recife, Guerra Peixe entrevistou maracatuzeiros, visitou terreiros e foi em busca de várias respostas para as questões que formulou. Uma delas diz respeito à distinção entre os dois tipos de maracatu, conceito que até hoje é utilizado para explicar e distinguir os grupos de baque virado e de orquestra. Esse processo, no entanto, não deve ser visto com naturalidade, pois entre a primeira publicação da obra Maracatus do Recife, em 1955, e o momento de sua reedição em 1981, muitos conflitos e debates ocorreram. Guerra Peixe foi alçado, entre boa parte dos intelectuais pernambucanos que discutiam sobre os maracatus, a um lugar simbólico que talvez nem ele mesmo desejasse ocupar, o de referência e autoridade para dizer como deve ser um maracatu. Tal questão pode ser mais bem percebida em outros trabalhos sobre o assunto, porém, ressalto que o próprio Guerra Peixe, em depoimento ao Museu da Imagem e do Som do Estado do Rio de Janeiro, afirmou ter sido o seu livro usado por intelectuais e maracatuzeiros como referência no processo de reativação do Maracatu Elefante, ocorrido em meados dos anos 1980. Sobre os usos do livro pelos maracatuzeiros, Isabel Guillen salienta:

E é nesse sentido, de autor que sabe quais são as verdadeiras tradições que ele é lido ainda hoje. Vai-se ao texto de Guerra 
Peixe para se confirmar qual a autêntica e legítima tradição dos maracatus. E por mais que Guerra Peixe tenha se horrorizado com o saber consagrado, com a recusa dos folcloristas de fazerem pesquisa de campo, seu livro encontra-se hoje entronizado como "o” saber sobre o maracatu. Esta afirmação pode ser comprovada na forma como se dá sua apropriação, não só de Guerra Peixe, mas de outros autores, por exemplo, pelo Maracatu Nação Leão Coroado, no site http:// www.leaocoroado.org.br/. Seu texto é recortado tematicamente, independentemente de suas questões com a historiografia, das querelas intelectuais que o texto estava travando ou debatendo. Determinada citação, ao ser recortada de seu debate, e posta num rol de autores consagrados, ao lado de Katarina Real ou Leonardo Dantas, vira autoridade. ${ }^{33}$

As relações entre os intelectuais e aqueles que fazem a cultura popular há muito tempo se estreitaram, e para se entender as manifestações culturais em atuação na atualidade, é preciso considerar estas influências recíprocas.

\section{O NÃO-PERNAMBUCANO - O SAMBA NO LUGAR DO ESTRAN- GEIRO.}

O debate sobre as origens do afoxé deve servir como parâmetro para que se estabeleça uma genealogia sobre os discursos que se fizeram em torno desta manifestação cultural, e ao mesmo tempo contextualizar uma disputa que ainda hoje ocorre no contexto político cultural pernambucano. Entretanto, se a opção pela discussão sobre as origens do afoxé for a de querer determinar um início para esta manifestação cultural, estaremos incorrendo em uma falsa questão, posto que nenhuma prática ou costume tem seu começo possível de ser localizado. A origem está irremediavelmente perdida no tempo e no espaço, fruto das mais diversas tramas do quotidiano. E por mais que tivéssemos como encontrar o ponto primordial de uma manifestação cultural, isso não bastaria para explicar a complexidade que uma invenção feita por homens e mulheres carrega consigo ao longo do tempo, como afirmou Rocha, "A origem de uma coisa não garante a explicação do seu estado atual”. ${ }^{34}$

O debate em torno das origens dos afoxés, entretanto, serve para mostrar os interesses e conflitos que ocorrem entre alguns intelectuais e afoxezeiros da atualidade. Serve também para enfocar os jogos políticos que acontecem entre aqueles e aquelas que pensam a cultura e as relações raciais em uma cidade marcada pelo fato de ser o berço de Gilberto Freyre, mentor da democracia racial, em que todos e todas, independentes de sua raça e cor seriam iguais. A rejeição ao afoxé, acusado de ser estrangeiro em terras recifenses (ou seja, baiano), pode ser considerada uma repetição do que ocorreu em anos anteriores 
com o samba. O próprio Gilberto Freyre em artigo intitulado "Recifense sim, subcarioca, não!”, publicado no Diário de Pernambuco, conclamava os pernambucanos a aderirem ao seu manifesto de repúdio às invasões culturais estrangeiras:

(...) O carnaval do Recife de 66 decorreu sob este signo terrível: perigo de morte! É que o assinalou uma descaracterização maciça, através da invasão organizada, dirigida e, ao que parece, até oficializada, dos seus melhores redutos de pernambucanidade: a invasão das escolas de samba (...) A traição ostensiva às tradições mais características de Pernambuco no que se refere a expressões carnavalescas. Um carnaval do Recife, em que comecem a predominar escolas de samba ou qualquer outro exotismo dirigido, já não é um carnaval recifense ou pernambucano: é um inexpressível, postiço e até caricaturesco carnaval sub-carioca ou sub-isso ou sub-aquilo (...). ${ }^{35}$

Outros intelectuais e estudiosos pernambucanos tomaram parte nesse ferrenho debate, ora mostrando que o samba também era pernambucano, como afirmou Bernardo Alves em polêmica tese, ${ }^{36}$ ora insistindo que mesmo não sendo da terra, o samba era feito por pernambucanos e que tudo é Brasil:

(...) Anote-se, por exemplo o domínio crescente das escolas de samba, no carnaval do Recife. surgem numerosas delas, cada qual aumentando, ano a ano, os seus efetivos. Ninguém vai admitir que se tenha estabelecido de repente, do Rio para o Recife, tão elevada - e especializada - corrente migratória. É, ao contrário, gente que vai deixando, por elas, os maracatus, os caboclinhos, seus clubes de ruas, suas troças e seus blocos (...) poderíamos dizer, simplesmente, que tudo é Brasil. Mais importante é dizer que tudo é povo (...). ${ }^{37}$

Assim como o samba, o afoxé também sofreu duras críticas por parte dos intelectuais "intransigentes defensores da pernambucanidade". Mas não se pode dizer que todas as vozes foram direcionadas contra os "invasores baianos". Katarina Real, na segunda edição de sua festejada obra, afirmou, mesmo sob o argumento de que o carnaval recifense era "possuidor de incrível poder integrador”, que o "afoxé baiano” deveria ser bem recebido:

Foi com certa surpresa que fui informada neste 1989 da entrada dos afoxés baianos no carnaval do Recife. Não tive a oportunidade de pesquisá-los, mas soube, através de vários dos seus líderes que os afoxés vem surgindo das novas organizações em prol duma "negritude" brasileira, como a Associação da Raça Negra do Recife e o Conselho de Entidades Negras de 
Pernambuco (Olinda) (...) Há alguns que criticam a presença dos afoxés no carnaval pernambucano, considerando-os como "intrusos da Bahia", um exemplo de "baianização" de nossa festa tradicional. Para mim, o caso dos afoxés representa mais um exemplo dos incríveis poderes de integração do carnaval recifense que já absorveu tradições antigas (...) por que não dar as boas vindas ao afoxé baiano? (...). ${ }^{38}$

Ora, em meio a intensos conflitos, tensões e disputas por parte dos afoxezeiros e militantes negros para afirmar a legitimidade dos afoxés, atribuindo aos mesmos significados próprios, distintos da baianidade a que lhe eram impingidos, o texto de Katarina Real não representava grande estímulo para que grupos como Alafin Oyó, Ara Odé ou Ylê de Egbá recebessem recursos e subvenções. Ainda mais quando se sabe de "certa rivalidade” alimentada por alguns jornais, TV's e rádios locais, entre pernambucanos e baianos. A meu ver o auge dessa disputa foi o projeto de lei do vereador Fernando Gondim, que limitava a veiculação do estilo musical denominado "axé music" e obrigava as bandas a terem frevos em proporção mínima de $60 \%$ do seu repertório. ${ }^{39}$ À esta cena acrescentem-se declarações diárias em televisões e rádios entre os anos 1992 a 1995 de condenação da música "estrangeira”, debates sobre a renovação do frevo e do carnaval pernambucano, além de medidas governamentais para incentivar os ritmos locais. As palavras do jornalista José Teles apontam o tom do que ocorria nos corações e mentes dos "pernambucanos" preocupados com o presente e o futuro de sua cultura e carnaval:

Enquanto defensores do carnaval autenticamente pernambucano continuam, ad nauseam, com o chauvinista repúdio à música baiana que tomou conta do, como se dizia nos tempos do entrudo, tríduo momesco do Recife, poucos param para refletir racionalmente sobre as causas da invasão dos baibunos. Por que a chamada axé music tomou o lugar do frevo, não apenas no Recife, mas no Brasil inteiro? ${ }^{40}$

Eis algumas boas razões para que os afoxezeiros e militantes das organizações negras fugissem da pecha de estarem defendendo a "música baiana”, ao mesmo tempo em que interagiam com a "cultura pernambucana" consubstanciada nos maracatus-nação. A entrada dos afoxés nos anos 1980 na mitificada cerimônia da Noite dos Tambores Silenciosos, em que praticamente todos os maracatus-nação se reúnem no Pátio do Terço na segunda feira de carnaval, é parte desta estratégia de busca da aceitação e legitimidade. A este recurso não se deve deixar de lado a informação de que diversos afoxezeiros afirmavam ser os afoxés agremiações autenticamente ligadas aos orixás, diferente de alguns maracatus que supostamente estavam perdendo suas raízes. A legitimidade para os 
afoxés no cenário recifense poderia estar ao lado da disputa com os maracatuzeiros, o que efetivamente aconteceu ao longo dos anos 1990. Esta disputa resultou na intervenção do Núcleo de Cultura Afro no ano 2001, quando os afoxés foram afastados em definitivo da referida cerimônia.

\section{OS AFOXEZEIROS E MILITANTES NEGROS: A BUSCA PELA ACEITAÇÃO E LEGITIMIDADE DOS AFOXÉS.}

Por mais que as origens não consigam explicar a complexidade dos afoxés em sua dinâmica atual, as discussões em torno destas nos indicam parte das estratégias utilizadas pelos afoxezeiros e militantes negros pernambucanos para afirmar a legitimidade de seus grupos. Ao mesmo tempo indicam os caminhos trilhados para mostrarem que os afoxés eram pernambucanos, reinterpretando as obras dos intelectuais que escreveram sobre o tema. A idéia de origem ganha novos contornos e sentidos entre os militantes negros e afoxezeiros, ora mostrando os afoxés como irmãos gêmeos dos maracatus, ora afirmando-os como cultura negra legítima.

Ao ponderar sobre o movimento negro pernambucano, Auxiliadora Silva discute sobre várias questões relacionadas à cultura negra, a exemplo da capoeira e dos maracatus. Ao citar o Elefante, em uma nota de rodapé, utiliza-se do conceito “maracatus-afoxés" bastante esclarecedor, por sinal, sobre a forma como ela e vários militantes negros compreendiam os afoxés e os maracatus na capital pernambucana. ${ }^{41} \mathrm{~A}$ este contexto deve-se também acrescentar a informação de que o Movimento Negro Unificado organizou, nos anos 1980, a campanha pela defesa da cultura negra através da participação direta de seus militantes no maracatu Leão Coroado e no afoxé Alafin Oyó. ${ }^{42}$ Esta relação pode ser mais bem entendida se outra informação a respeito destes grupos for acrescentada: em vários momentos nos anos 1980 o presidente do Afoxé Alafin Oyó e do Maracatu Leão Coroado eram militantes do combativo agrupamento negro surgido no final dos anos 1970, o Movimento Negro Unificado. ${ }^{43}$

Juntamente com os afoxezeiros, os militantes negros tomaram posições diversas em relação aos diferentes ataques desferidos contra os afoxés pernambucanos. A ação mais evidente no campo das idéias diz respeito ao uso dos autores que escreveram sobre os afoxés e os maracatus, principalmente pelo fato de que estes eram as principais referências na campanha de deslegitimação de grupos como o Alafin Oyó e Ylê de Egbá. Um dos autores mais usados por estes militantes foi justamente Guerra Peixe, principalmente devido aos contornos que sua obra ganhou durante os anos 1970 e 1980 . Usar uma "autoridade intelectual" na defesa de uma prática cultural é também o reflexo de estratégias de inserção social e busca de legitimidade política, e ninguém melhor do que Guerra Peixe 
para atribuir tais valores aos afoxés em Pernambuco, mesmo que os afoxezeiros e militantes negros estivessem se apoiando na idéia de origem como discurso legitimador de uma prática.

Está claro a meu ver que a “autoridade” de Guerra Peixe é forte motivo para que muitos militantes dos movimentos negros em Pernambuco, juntamente com vários afoxezeiros se apropriem de seu discurso sobre os afoxés e maracatus para buscarem legitimidade dos primeiros junto aos segundos, principalmente quando há fortes questionamentos entre os intelectuais pernambucanos sobre a "baianidade" congênita dos afoxés. Mas o argumento em defesa dos afoxés não ficou preso apenas nas reinterpretações dos estudiosos, uma vez que a identidade negra e a relação cultural com a África motivavam a afirmação de outras idéias e justificativas. Em panfleto alusivo aos afoxés, feito pela Prefeitura da Cidade do Recife, um destacado e reconhecido militante negro expõe suas razões para que os afoxés fossem aceitos e bem recebidos em sua própria casa, o Recife:

(...) Se a escravidão isolou e segregou os indivíduos, também determinou um esforço coletivo de reação quanto ao regime de vida que lhes foi imposto. Para além da resistência política, a mãe África nos presenteou com a sabedoria milenar dos búzios, o oráculo divino que orienta a religião afro e traz a fala das divindades africanas para o nosso cotidiano. Trouxe o conhecimento da vida comunitária traduzida em quilombos espalhados por todo o território nacional, e nos deu presentes preciosos como as ricas manifestações culturais, tão singulares, a exemplo do nosso afoxé.

No Recife, essa rica expressão do povo negro é irmã do maracatu, essa meditação de rua chamada afoxé nasce por dentro dos primeiros cortejos de maracatu de baque-virado (manifestação surgida a partir da instituição dos reis de Congo, utilizada para dominar os negros, mas transformada em expressão de liberdade pela comunidade).

A palavra de origem sudanesa áfohsheih aparece em virtude da influência do povo sudanês sobre os bantus, utilizada para designar nação e grupos administrados por governador negro. Seria, então, afoxé de África a festa profano-religiosa. Talvez venha daí a relação com o maracatu.

O afoxé é hoje expressão artístico-religiosa e também carnavalesca da população negra com maior definição estética de nação africana. A concepção que faz a beleza do afoxé é tão africana quanto as nações do candomblé brasileiro. ${ }^{44}$

Este texto de Lindivaldo Júnior, militante negro reconhecido por sua trajetória no MNU, e também por ter estado à frente de vários eventos de valorização da cultura negra pernambucana, pode ser visto como uma junção dos três gran- 
des argumentos utilizados pelos afoxezeiros e entidades negras no processo de afirmação dos afoxés e da busca de legitimidade destes perante a sociedade local. Os afoxés são legítimos por serem irmãos gêmeos dos maracatus, terem a mesma origem e, sobretudo por já terem existido nestas terras em um passado remoto e distante. Eis o primeiro grande argumento, fruto das reinterpretações de autores como Edison Carneiro e Guerra Peixe. Mas os afoxés também são legítimos em Pernambuco por serem cultura negra e ao mesmo tempo africana: é um dos muitos "presentes valiosos" legados pelos escravos trazidos ao Brasil.

Além disso, os afoxés são pernambucanos por estarem intimamente ligados ao candomblé e aos orixás, e como tal, merecedores do respeito daqueles que entendem a importância das divindades na sociedade pernambucana. Estes argumentos, por mais que possam ser divididos em três grandes grupos não são excludentes, a ponto de terem sido usados em um único texto por Lindivaldo Júnior. Não importam as contradições existentes no mesmo, tampouco os desencontros com a documentação coletada sobre o tema, ou as afirmações etnocêntricas de que um povo influenciava outro, sabe-se lá por que razão. Lindivaldo Júnior afirma e batalha pela legitimidade dos afoxés, buscando para os mesmos uma dignidade de manifestação cultural legítima.

No processo de legitimação dos afoxés, outra forte marca e argumento utilizado pelos militantes negros e afoxezeiros diz respeito a idéia de que grupos como Alafin Oyó, Ylê de Egbá e Ara Odé não são apenas agremiações festivas ou carnavalescas, mas sinônimos do candomblé:

(...) AFOXÈ - e o que é o afoxé? "Para participar, seria interessante que todos os integrantes fossem ligados a um terreiro de candomblé”, diz Sidney Felipe, membro do Alafin Oyó, de Peixinhos, Olinda. Essencialmente uma manifestação religiosa, o afoxé era uma maneira de burlar a repressão à religião de Orixá. Hoje, os afoxés saem às ruas durante o carnaval. E é bom que se cuidem das obrigações essenciais dedicadas ao orixá patrono e a Exu, para que as coisas corram tranquilamente durante o desfile, arremata Sidney Felipe. ${ }^{45}$

Esse argumento também está presente nas palavras de ilustres afoxezeiros, como Rivaldo Pessoa, antigo afoxezeiro e um dos fundadores do Alafin Oyó, e Fabiano, o seu atual dirigente. Para estes destacados afoxezeiros:

“(...) o afoxé transcende o carnaval, pois é uma representação das práticas religiosas afro-descendentes, ligada ao candomblé”. Afirmam ainda que o percurso histórico dos afoxés de Pernambuco revela que eles ficaram desaparecidos por muito tempo, voltando ao carnaval pelo esforço do MNU, que, nos finais do ano de 1970, iniciou um processo de resgate das 
tradições afro-descendentes. Assim, concebe-se o afoxé como sendo um “candomblé de rua”, uma maneira de louvar a natureza; uma forma de, através da alegria, levar ao público a cultura milenar, a cultura do povo africano. ${ }^{46}$

Conforme afirmei acima, os afoxezeiros e militantes negros, como bons estrategistas, manipularam a história e os discursos de origem a seu favor, construindo para os afoxés as condições para sua legitimidade e aceitação, enfrentando preconceitos, escassez de recursos e disputas internas pela hegemonia entre os grupos. A idéia de origem, nesse aspecto, ganha a feição de discurso para conferir legitimidade aos afoxés, posto que se alguns intelectuais pernambucanos afirmavam ser esta manifestação cultural baiana por nascimento, os militantes negros vão afirmar outro discurso, de que o Alafin Oyó, Ilê de Egbá e Ara Odé são irmãos gêmeos dos maracatus. Portanto, pernambucanos e tão legítimos quanto estes.

Outra questão posta para a afirmação dos afoxés diz respeito à idéia de que estes constituem autêntica cultura negra, e como tal merecedora de todas as atenções possíveis por parte dos negros e negras, sejam eles e elas de onde forem. Os afoxés também são candomblés de rua, e continuam mantendo os vínculos com o sagrado em Pernambuco, diferentemente do que vem ocorrendo na Bahia. Este argumento é recorrente nas falas dos atuais dirigentes das entidades negras locais e dos afoxezeiros mais destacados, que continuam buscando a construção de dias melhores para os afoxés pernambucanos. Para estes, os grupos baianos, sobretudo o Filhos de Gandhy, não são mais dotados da íntima relação com os candomblés.

\section{CONCLUSÃO: AFOXÉS LEGÍTIMOS NA “TERRA DO FREVO E DO MARACATU”.}

Os afoxezeiros mostraram-se dispostos ao embate na busca pela legitimidade, mesmo que enfrentando momentos difíceis para a manutenção e a própria existência dos grupos. Construíram discursos, reinterpretaram a história e constituíram uma associação (a União dos Afoxés de Pernambuco - UAPE) que lhes permitiu gozar de boa visibilidade e aceitação em Pernambuco. Se nos anos 1980 não existia mais do que uma dezena de grupos, hoje seguramente já passam da casa dos sessenta e constituem presença garantida em eventos como a Terça Negra, organizada pelo Movimento Negro Unificado no Pátio de São Pedro (no coração da cidade do Recife), assim como têm lugar garantido nas programações carnavalescas das principais cidades da região metropolitana recifense. No ano de 2007 o Alafin Oyó foi escolhido para figurar no seleto rol das atrações do Festival de Inverno de Garanhuns. Vários grupos gravaram Cd's e viajaram em 
turnês para a Europa, a exemplo do Ilê de Egbá. Pode-se afirmar que, se comparado com outras manifestações culturais, os afoxés encontram-se em melhor situação do que os ursos, caboclinhos e bois de carnaval. Mas esta realidade não foi fruto do acaso, ou da ação isolada dos afoxezeiros e militantes negros. Há que se levar em conta outras variáveis, como o crescimento dos movimentos negros organizados e a luta contra o racismo no país, além da aprovação de leis como a 10639/2003, primeiro decreto-lei apresentado pelo Governo Lula, que institui a obrigatoriedade do ensino da História e da cultura afro-brasileira.

O reconhecimento oficial por parte do Estado de que o país não vive uma democracia racial, como se apregoava no passado, também é outro importante elemento para se entender a aceitação atual dos afoxés em Pernambuco, bem como o favorável contexto em que se encontram. ${ }^{47}$ Não tenho como afirmar, contudo, que este é um tema esgotado, acreditando que novos estudos devem ser feitos para que a história dos afoxezeiros possa ser mais bem contada. Esta é apenas uma pequena parte do que pode ser escrito. Com a palavra, os historiadores do presente e do futuro.

\section{NOTAS}

2 Para uma discussão sobre as origens do maracatu, ver: COSTA, F. A. Pereira da. Folk - lore pernambucano. Subsídios para a história da poesia popular em Pernambuco. Recife, Arquivo Público Estadual, 1974 [1908]; PEIXE, Guerra. Maracatus do Recife. Recife, Prefeitura da Cidade do Recife/ Irmãos Vitale, 1980, $2^{a}$ edição; REAL, Katarina. O folclore no carnaval do Recife. Recife, Fundação Joaquim Nabuco Ed. Massangana, 1990, $2^{a}$ edição; BRANDÃO, Theo. Folguedos natalinos. Maceió, Depto de assuntos culturais / Conselho Federal de Cultura, 1973; ARAÚJO, Alceu Maynard. Folclore Nacional. Danças, Recreação, Música. Vol II. São Paulo, Edições Melhoramentos, 1967, 2ª . Edição. Esses autores e o modo como abordaram a questão das origens dos maracatus foram por mim discutidas em: LIMA, Ivaldo Marciano de França. Maracatus e maracatuzeiros: desconstruindo certezas, batendo afayas e fazendo histórias. Recife, 1930 - 1945. Recife: Edições Bagaço, 2008; LIMA, Ivaldo Marciano de França. Maracatus-nação: ressignificando velhas histórias. Recife: Bagaço, 2005.

${ }^{3}$ Câmara Cascudo afirma que "... A unanimidade das fontes brasileiras indica a capoeira como tendo vindo de Angola”. CASCUDO, Luis da Câmara. Folclore do Brasil. Rio de Janeiro: Editora Fundo de Cultura, 1967, p. 181. Outro autor que também afirma a origem africana da capoeira, mas em uma perspectiva diferente, qual seja, de que o local em que se pratica a versão mais próxima das origens africanas se encontra na Bahia, foi CARNEIRO, Edison. Dinâmica do folclore. Rio de Janeiro: Civilização Brasileira, 1985, p. 49 - 54. Entre os que defendem uma origem nacional há vários autores: AREIAS, Almir. O que é capoeira. São Paulo: Brasiliense, 1983, p. 19; RIOS FILHO, Adolfo Morales. O Rio de Janeiro imperial. Rio de Janeiro: Ed. A Noite, s/d. Os melhores estudos sobre a capoeira podem ser vistos em: SOARES, Carlos Eugênio Líbano. A negregada instituição - os capoeiras no Rio de Janeiro. Rio de Janeiro: Coleção Biblioteca Carioca/Prefeitura da Cidade do Rio de Janeiro, 1994; SOARES, Carlos Eugênio Líbano. A capoeira escrava e outras tradições rebeldes no Rio de Janeiro ( 808 - 1850). Rio de Janeiro: Ed. Unicamp, 2004. 
${ }^{4}$ VIEIRA FILHO. Raphael Rodrigues. Folguedos negros no carnaval de salvador ( 880 - 1930) in: SANSONE, Livio. SANTOS, Jocélio Teles dos (orgs). Ritmos em trânsito - sócio-antropologia da música baiana. São Paulo: Dynamis Editorial; Salvador: Programa A cor da Bahia/ Programa S.A.M.B.A, 1997, p. 39.

${ }^{5}$ VIEIRA FILHO. Raphael Rodrigues. op cit, p. 50.

${ }^{6}$ Idem.

${ }^{7}$ LODY, Raul Giovanni. Afoxé. Cadernos de folclore. Rio de Janeiro: Funarte, 1976.

${ }^{8}$ Idem, p. 43.

9 ARAÚJO, Alceu Maynard. Folclore Nacional. Danças, Recreação, Música. Vol. II. São Paulo: Melhoramentos, 1967, p. 305..

${ }^{10}$ CARNEIRO, Edison. Folguedos tradicionais. Rio de Janeiro: Conquista, 1974, p. 124.

I'Idem, p. 123. Segundo Raphael Filho, esta descrição dos afoxés feita por Carneiro foi baseada em informações dadas por Hilário Reimídio. Para Raphael Filho, este último era "um velho africano..." e que por isso mesmo "... não há razão para se duvidar dessas informações". Em meio ao texto deste autor percebem-se a força das representações construídas por outros autores em torno da origem dos afoxés e de sua estreita vinculação com o sagrado. Por mais que este mesmo autor afirme em outros trechos de seu trabalho a existência de mudanças em meio aos afoxezeiros e seus afoxés. VIEIRA FILHO, Raphael Rodrigues. op cit, p. 52.

${ }^{12}$ CARNEIRO, Edison. Dinâmica do folclore, p. 47.

13 CASCUDO, Câmara. Vaqueiros e cantadores. Rio de Janeiro: Ediouro, 2000;

${ }^{14}$ LODY, Raul Giovanni. op cit, p. 18 - 19.

${ }^{15}$ HALL, Stuart. Da Diáspora. Identidades e mediações culturais. Belo Horizonte: Ed. UFMG, 2003, p 391.

${ }^{16}$ LODY, Raul Giovanni. op cit, p. 06

${ }_{17}$ RAMOS, Arthur. O negro Brasileiro. Recife: Massangana, 1988, p. 250. Sobre a antropologia evolucionista, ver: CASTRO, Celso. Evolucionismo cultural. Textos de Morgan, Tylor e Frazer. Rio de Janeiro: Jorge Zahar, 2005.

${ }_{18}$ RISÉRIO, Antonio. Carnaval ijexá; notas sobre afoxés e blocos do novo carnaval afrobaiano. Salvador: Corrupio, 1981, p. 56.

19 RISÉRIO, Antonio. op cit, p. 64. Sobre a tradição entendida como uma invenção, ou seja, que estabelece uma relação "artificial" com o passado, ver: HOBSBAWN, Eric; RANGER, Terence (orgs). A invenção das tradições. Rio de Janeiro, Paz e Terra, 1984.

${ }^{20}$ VIEIRA FILHO, Raphael Rodrigues. op cit, p. 52.

21 GUERREIRO, Goli. A trama dos tambores - a música afro-pop de Salvador. São Paulo: Editora 34, 2000, p. $71-72$.

22 Idem, p. 72

${ }^{23}$ Idem, p. 77

${ }^{24}$ ARAÚjO, Alceu Maynard. op cit, p. 304.

${ }^{25}$ CARNEIRO, Edison. Folguedos tradicionais, p. 121.

${ }^{26}$ CARNEIRO, Edison. Dinâmica do folclore, p. 47.

${ }^{27}$ CARNEIRO, Edison. Folguedos tradicionais. p. 122

${ }^{28}$ VIEIRA FILHO, Raphael Rodrigues. op cit, p. 51 - 52.

29 LODY, Raul Giovanni. op cit, p. 06

30 BARTH, Fredrik. A análise da cultura nas sociedades complexas in: LASK, Tomke (org). O guru, o iniciador e outras variações antropológicas. Rio de Janeiro: Contracapa, 2000, p. 108.

31 Uma boa discussão a respeito do papel do antropólogo no campo pode ser vista em: PRITCHARD, Evans Edward E. Algumas reminiscências e reflexões sobre o trabalho de campo in: Bruxaria, oráculos e magia entre os azande. Rio de Janeiro: Jorge Zahar, 2004.

32 PEIXE, Guerra. Maracatus do Recife. Recife: Prefeitura da Cidade do Recife/ Irmãos Vitale, 1980, $2^{\mathrm{a} e d i c ̧ a ̃ o, ~ p . ~} 25-26$. 


\section{REVISTA ESBOÇOS Volume 16, № 21, pp. 89-110 - UFSC}

${ }^{33}$ GUILLEN, Isabel. Guerra Peixe e os maracatus: nacionalismo musical e folclore no Brasil. Trabalho apresentado no II Encontro Nacional da ABET, 2004, Salvador. Anais eletrônicos do II Encontro Nacional da ABET. Etnomusicologia: lugares e caminhos, fronteiras e diálogos. 2004. Sobre Guerra Peixe, ver também: GUILLEN, Isabel. Guerra Peixe e os maracatus no Recife: trânsitos entre gêneros musicais ( 1930 - 1950). ArtCultura. Revista de história, cultura e arte. Uberlândia: vol. 09, n |4, jan jun, 2007. O depoimento de Guerra Peixe está depositado no MISRJ: Depoimentos, fita O I, número de localização: vi 002 19.1. O depoimento foi tomado em 20/10/1 992. O Diário de Pernambuco, de 07/02/ 1986 registra o ressurgimento das atividades do Maracatu Elefante no Recife e mostra parte dos que compuseram a comissão pela reativação do citado grupo, figurando dentre outros nomes os de Gilberto Freyre e Evandro Rabelo.

${ }^{34}$ ROCHA, Everardo P. Guimarães. O que é mito. São Paulo: Brasiliense, 1985.

35 FREYRE, Gliberto. Diário de Pernambuco, 27/02/1966 apud: SILVA, Leonardo Dantas. Estudo introdutório. in MAIOR, Mário Souto; SILVA, Leonardo Dantas. Antologia do carnaval do Recife. Recife: Massangana, 1991, p. $84-85$.

${ }^{36}$ ALVES, Bernardo. A pré-história do samba. Petrolina, edição do autor, 2002.

${ }^{37}$ OLIVEIRA, Waldemar. "A recriação popular". Boletim da Comissão Pernambucana de Folclore. Recife: ano II, vol 02, nº 0I, (1966), p. I2.

${ }^{38}$ REAL, Katarina. O folclore no carnaval do Recife. Recife: Ed. Massangana, 1990, $2^{\text {a }}$ edição, p. $200-$ 201.

${ }^{39}$ Frevo declara guerra a axé-music. Jornal do Brasil, 24//2/I992 apud: GUERREIRO, Goli. op cit.

40 TELES, José. O carnaval pernambucano precisa ser reinventado. Suplemento Cultural, Recife: Diário Oficial, fevereiro de 1995, p. 05.

${ }^{4}$ SILVA, Maria Auxiliadora Gonçalves. Encontros e desencontros de um movimento negro. Brasília: Fundação Palmares, 1994, p. 63.

${ }^{42}$ Sobre o Leão Coroado ver o documentário de Raul Lody, Maracatu Leão Coroado, produzido pela FUNARTE, 1987; Sobre o Alafin Oyó há um vídeo da TV Viva - Centro de Cultura Luiz Freire, de 1989.

43 Marta Rosa, destacada dirigente do MNU foi presidente do Afoxé Alafin Oyó no final dos anos 1980 e Marta Almeida, outra combativa militante, dirigiu o grupo entre os anos 1991 a 1993. Telma Chaisse integrou a junta provisória do Maracatu Leão Coroado entre os anos 1988 e 1989.

${ }^{44}$ JÚNIOR, Lindivaldo. Afoxés de África no Recife in: Afoxé - encanto e resistência. Folder distribuído pela Prefeitura da Cidade do Recife. Encontra-se depositado na Casa do Carnaval.

${ }^{45}$ CAMPOS, Jazilda. "Touche pas a mon pote!". Suplemento Cultural, Recife: Diário Oficial, novembro de 1987, p. 04.

${ }^{46}$ SILVA, Maria Auxiliadora Gonçalves. Arqueologia da memória: resgate da mãe África. Tese de doutorado em antropologia, Recife: UFPE, 2007, p. 152.

${ }^{47}$ O Governo Brasileiro reconheceu oficialmente, em 2003, a existência do racismo no país criando a SEPPIR, Secretaria Especial Para a Promoção da Igualdade Racial. Ressalte-se que o primeiro decretolei apresentado pelo Governo Lula, também no ano de 2003, foi a lei 10639/2003 que institui a obrigatoriedade do ensino da História e da cultura afro-brasileira. 